load in the space suit and the carbon dioxide level in the helmet." Another false prophecy, derived from experiments in aeroplanes, was that a period of weightlessness would reduce tolerance to subsequent violent deceleration on reentry into the atmosphere, but though it reached a maximum of $8.2 \mathrm{~g}$ it was well tolerated.

The remaining article, by George J. Kidera, ${ }^{4}$ shows that the most frequent medical causes of commercial pilots being grounded are cardiovascular (52\%) and psychiatric (17\%).

\section{Plan for Hospitals}

A working party set up jointly in 1965 by the King Edward's Hospital Fund and the Institute of Hospital Administrators was asked " to consider how, if at all, the present pattern of hospital administration might need alteration in the light of the changes that have taken place since 1948 and of further changes that may be brought about during the next fifteen years by the development of District Hospitals." Its twelve members included one medical man, Professor John Anderson, of King's College Medical School, and two hospital matrons, the others being lay hospital administrators. The working party set themselves the task of considering existing systems of management of hospitals at district level, suggesting changes that might be required in these systems, and considering a management pattern for the future, bearing in mind the advent of district hospitals.

In its report, ${ }^{1}$ recently published, the working party identified three features of the existing arrangements which it regards as unsatisfactory and tending to hamper efficient and economic management. They are, firstly, over-use and misuse of the committee system; secondly, the absence of a clear definition of the roles and responsibilities of the various senior officials and of their relationship one to another ; and, thirdly, the absence in the organization of any one official holding overall responsibility and.authority. The working party's recommendations are designed to overcome these defects and also to provide for the closer association which it foresees will develop between the hospital and the other health and welfare services in the community. Its proposals rest on "two basic assumptions about the hospital service 15 years hence." The first is that the Ministry or some other central authority will continue to administer the service, the district hospital remaining the lowest tier of a three-tier structure, and the second that the best management structure for a district hospital will be "that which extracts from scarce resources of money, labour, and equipment the maximum possible benefit for the patient."

It is proposed that the hospital management committee should be replaced by a district hospital board. This would still be appointed by " the regional agent of the central health authority," but would have far fewer members, consisting of an appointed chairman and seven other members, three of whom would be on it ex officio. There would be two community advisory committees, one concerned with general medical matters and co-operation with other health and welfare services, the other with the interests of patients and co-operation with the local community. The chairman of each of these committees would be ex officio a member of the board.

\footnotetext{
- The Shape of Hospital Management in 1980. King Edward's Hospital Fund for London. 1967. London.
}

The task of the board is seen as "to administer the moneys allotted to it and formulate the necessary policy to run the District Hospital." Executive function would be delegated to a general manager responsible for running the hospital, who would also be an ex-officio member of the hospital board. The general manager would be assisted by four directors of service in charge of medical and paramedical services, nursing services, finance and statistical services, and general services. These posts would be full-time appointments, though the director of medical and paramedical services might initially need to be part-time. A hospital medical services committee would be appointed by the senior clinical staff to advise the director of medical and paramedical services.

The late Professor J. M. Mackintosh, who contributed much to the study of medical administration, often claimed that there were only two countries in which the head of the medical services was not a doctor-the United Kingdom and Abyssinia. Whether this is so or not, it is certainly true that in Britain-more particularly the southern half of it-there is a body of opinion which holds that in hospitals at all events the doctor's place is in the ward and the operating-theatre, not the board-room. Most doctors are in no doubt that the primary function of a hospital is to deploy certain forms of investigation and treatment in the most effective way. The notion that they are really specialized institutions to be run by appropriately qualified managers with the help of doctors is not true. Undoubtedly lay officials have an essential role in the successful management of hospitals, but it should not be the dominant one.

The working party's report, though presented as a contribution to long-term planning, is essentially a presentation of the case for lay administration of hospitals. As such, it ought to serve a useful purpose in stimulating the medical profession to clarify its thinking on the shape of things to come.

\section{Health Education of Asian Immigrants}

Hazards to which newly arrived Asian immigrants are prone include pulmonary tuberculosis ${ }^{12}$ and venereal disease, ${ }^{3}$ the effects of intestinal parasites-in particular anaemia from hookworm infestation ${ }^{4}$ - and accidents due to unfamiliar surroundings. ${ }^{5}$ Thus health education ${ }^{6}$ could make a valuable contribution to the wellbeing of these people.

The newly arrived immigrant may be seen by his own countrymen, by a family doctor with whom he is urged to register shortly after arrival, by local-authority medical, social, or educational workers, and by staff of the Ministries of Labour or Social Security. If all bear in mind the risk he may be running, they can offer preventive measures or treatment by the appropriate services. A recent symposium held by the Health Education Section of the Royal Society of Health in Bradford showed that during three years of keeping specific records the infant mortality rate among children born locally to Asian immigrants had fallen to that of the English population of similar housing and employment background; and numbers of new notifications of pulmonary tuberculosis and venereal disease were declining rapidly. This had bcen achieved in part by special attention to the organiza- 